\title{
Rapid and Sensitive Electrochemical Monitoring of Tyrosine Using NiO Nanoparticles Modified Graphite Screen Printed Electrode
}

\author{
Asghar Parsa ${ }^{1}$, Niloufar Akbarzadeh-Torbati, ${ }^{1, *}$,Hadi Beitollahi ${ }^{2}$ \\ ${ }^{1}$ Department of Chemistry, University of Sistan and Baluchestan, P.O. Box 98135-674, Zahedan, Iran \\ ${ }^{2}$ Environment Department, Institute of Science and High Technology and Environmental Sciences, \\ Graduate University of Advanced Technology, Kerman, Iran. \\ *E-mail: n.akbarzadeh@chem.usb.ac.ir
}

doi: $10.20964 / 2019.02 .42$

Received: 8 April 2018 / Accepted: 16 July 2018 / Published: 5 January 2019

$\mathrm{NiO}$ nanoparticles was employed for the sensitive determination of tyrosine. The electrochemical response characteristics of the modified electrode toward the tyrosine was investigated by cyclic voltammetry (CV), chronoamperometry (CHA) and differential pulse voltammetry (DPV). The response of the electrochemical sensor for the tyrosine was found to be improved significantly in comparison with those obtained at graphite screen printed electrode (SPE). The oxidation peak current increased linearly in the range of $0.15-450.0 \mu \mathrm{M}$, with the detection limits of $0.1 \mu \mathrm{M}$.

Keywords: Tyrosine, NiO nanoparticles, Voltammetric sensor, Graphite screen printed electrode

\section{$\underline{\text { FULL TEXT }}$}

(C) 2019 The Authors. Published by ESG (www.electrochemsci.org). This article is an open access article distributed under the terms and conditions of the Creative Commons Attribution license (http://creativecommons.org/licenses/by/4.0/). 